\title{
Discussion on the Cultural Construction of Chain Hotel Management based on Enterprise Identification
}

\author{
Qianjie Liu \\ Xijing University, Xi'an, 710123, China \\ Email: 394413014@qq.com
}

\begin{abstract}
With the rapid development of chain hotel enterprises, the urgent need of high quality chain hotel management personnel. It is an urgent need to solve the problem that Chain hotel management professional personnel training how to meet the needs of the enterprise. In this paper, we introduce the corporate identity system to strengthen the cultural construction of the hotel management, so as to cultivate the professional talents to meet the needs of the enterprise, to create a good atmosphere for the society, schools and enterprises.
\end{abstract}

Keywords-Chain hotel management major; Professional culture; Enterprise identification system

\section{INTRODUCTION}

With the progress of the society and the change of the times, the development of hotel enterprises is particularly prominent. According to the analysis of the world chain hotels, the hotel industry in China will become one of the fastest growing countries in the world. In order to meet the needs of the future hotel talents in higher vocational colleges[1], re-examine the chain hotel management professional training, based on the original talent, to constantly innovate and practice, as a chain of hotel management professional talents of higher vocational colleges is closely integrated with the market and cultivate talents, need to continue cooperation with enterprises the depth of the professional into the enterprise, the students in the learning theory of culture at the same time, the enterprise culture into the professional culture, cultivate students conforms to the enterprise needs to have a theory of culture, professional skills and high-quality talent[2].

The development of modern enterprise culture is mainly based on CIS (Identity System Corporate), show the company's image, behavior, brand and other aspects ,human society will constant evaluation and testing it[3-4]. Combined with the development of chain hotel management, the combination of corporate culture and hotel chain management, and discus a new model and approach to the management of Higher Vocational hotel chains[5].

CIS (Corporate Identity System) in 1950 s by the United States IBM company first proposed[6], through the development of half a century, in different countries, different regions have different descriptions. CIS is consist of MI(Mind Identity)、BI(Behavior Identity)、 VI(Visual I-identity) [7-9]. These three parts interact with each other, is the organic whole, which is responsible for building and improving the image of the enterprise. Among them, the
MI mainly stresses on the spiritual idea, is the enterprise operation idea, represents the enterprise's soul, the enterprise value in the society; BI is mainly focused on the people, is the enterprise to people, things to manage the dynamic system, in the whole system, BI and social contacts, directly reflect the image of the enterprise in the public, has a profound impact; VI mainly focused on the material, is the use of human vision to judge the enterprise's mental outlook and image, generally through the media function to complete[10].

CIS can be divided into three systems, that is, MIS(Mind Identity System), BIS(Behavior Identity System), VIS(Visual I-identity System) [11]. MIS is mainly the unification about enterprise in the industry competition to reflect the spirit of enterprise, corporate culture, corporate goals and character, etc...The value system of some personality after long-term exercise in the enterprise practice and the formation of the spirit and has its own basis for future development of enterprises) enterprise behavior recognition system BIS(Behavior Identity System), the concept of enterprise effective guidance, according to their own characteristics[12], so that enterprises can be recognized by the majority of the public behavior through the practice of enterprise, to show the spirit of our company and the dissemination of corporate culture, to reflect the enterprise competition in the industry, recognized in the public, establish a good corporate image) enterprise visual identification system VIS(Visual I-identity System), is a concrete manifestation of the MIS Visually, the concept and cultural factors such as enterprise with vision to spread the enterprise into a specific symbol to show the concept of enterprises Industry image[13], showing the style and personality of the enterprise in the whole MIS system, BIS is in the core position, leading the enterprise VIS and CIS and MIS in behavior and vision of the specific performance of the three is a common existence[14].

\section{CHAIN HOTEL MANAGEMENT PROFESSIONAL CULTURE AND CIS}

Professional culture refers to the same value idea and behavior of all the students in a university, which makes the professional students form one kind of professional characteristics and individual culture with other majors. The specific performance can be divided into spiritual culture, institutional culture and material culture.

The spiritual culture is at the core position, guiding the system culture and material culture. The higher education 
not only pays attention to the professional education, but also pays attention to the cultural construction.

Chain hotel management major is to train the hotel chain management as the goal, to develop students with a strong sense of progress, and strive to forge ahead, continue to strengthen learning, for their own ideals and goals. Chain hotel management professional culture and CIS organic combination, to cultivate students with chain hotel management professional culture concept, the students should start from the bottom, in the ideal and reality coexist, to adjust their mentality, can not impetuous, once the job and their ideal gap, the teacher should be based on professional culture to guide students from the most basic position to start, to overcome the students psychological barrier, new work environment and other factors, through their own efforts, to business and environmental knowledge, and gradually improve the personal ability, so as to promote the foundation.

\section{THE CULTURAL CONSTRUCTION OF CHAIN HOTEL MANAGEMENT SPECIALTY}

Chain hotel management professional and cultural construction is not completely abandon the original outstanding culture, but to strengthen the professional construction, so that the professional development of more prospects, and combined with the actual situation of enterprises to create a school enterprise mutual financial professional culture. According to the concept of enterprise, image, style and other factors into the professional development, according to the enterprise culture characteristic of the professional culture of the concept of the three subsystems of the chain hotel management professional image, ideas and actions, etc., so that the professional culture can adapt to corporate culture, into the corporate culture, as shown in Fig .1.

\section{A. The establishment of chain hotel management concept (MI) identification of professional culture}

MI hotel chain enterprise culture refers to the hotel chain enterprises in the pursuit of economic benefits, create brand, Corporate image, a representative group of the establishment of the spiritual power, so that enterprises in the competition with core competence in the professional construction of the need to MI the power of spirit as support, cultivate students' teamwork, the spirit of dedication, and the spirit of enterprise culture, enterprise cooperation, School enterprise integration, highlighting the characteristics of occupation education.

For chain hotel management professional spiritual and cultural construction, the Institute has always carried out the education department to the higher vocational education quality of teaching quality, shoulder the task of training high skilled talents for production, construction, service and management. Insist on the implementation of the Hong De, Duxue, and strong extension of the new concept, establish the slogan and the establishment of the exhibition hall in honor of the training venue, highlighting the hotel management and the development of human society, the establishment of school enterprise cooperation training venues, let students zero distance contact corporate culture, pay attention to cultivate students' quality management level, service consciousness, help students to better adapt to the development of business and industry professional, so that students in thinking and establish a scientific concept of occupation, in order to better integrate into society and lay a good foundation.

\section{B. Building theory based on behavior recognition (BI) of professional culture}

The BI culture of hotel chain hotel is a cultural phenomenon which is formed by enterprises in the management, publicity and practice. The school will be integrated into the behavior culture of the enterprise on the basis of its own culture, and it has made the reform of the behavior and cultural construction of the chain hotel management.

The practice of the chain hotel, after a school, after a school, after a school, after a school, after a school, after a school, after a school, after a school, after a study, can be exchanged to other posts, through a study period, after a school, can be exchanged to other posts, through basic services and job management, training students in the society. Management, so that students in school The theoretical knowledge of learning and the culture of the enterprise can be brought into play in the enterprise, the enterprise behavior recognition into the professional culture, so as to establish a good professional image[15].

\section{The establishment of basic and visual identity (VI) of professional and cultural image}

Chain hotel enterprise's VI culture is divided into two categories, one is the chain hotel visual basic elements of design, chain enterprises must have a unified logo, logo and image identification to establish a good, complete unity of the hotel image has important significance; two is the chain of hotel application design, including chain hotel internal office, external environment, image, public relations, guest room management, management and other systems. In the professional construction, the introduction of hotel chain hotel VI culture, hotel management professional hotel room laboratory, the standard of the hotel standard room and have a warm and creative, to train students to design and management, with a modern chain of the logo and a variety of innovative internal management. In the course of the experiment, the students in the course of the experimental training, including the hotel etiquette, service, management and other projects to carry out group simulation training, students can experience in the training of the hotel chain culture, for the future to lay a solid foundation for the post practice 


\section{Figures and Tables}

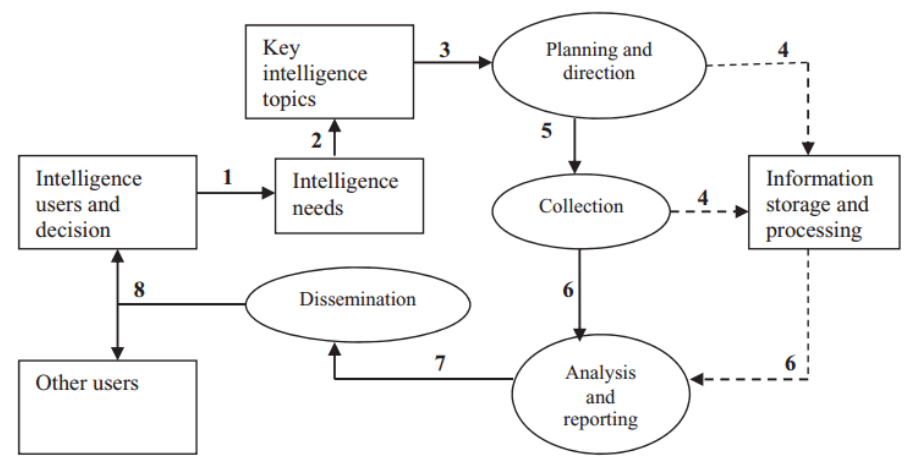

Figure 1. Competitive intelligence cycle

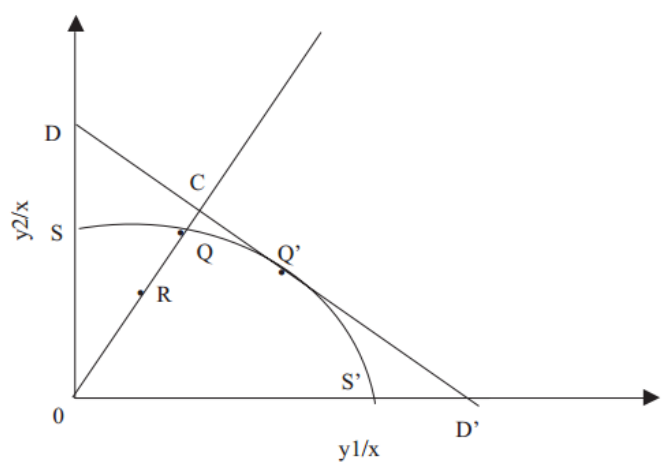

Figure 2. Identifying technical and allocative efficiency.

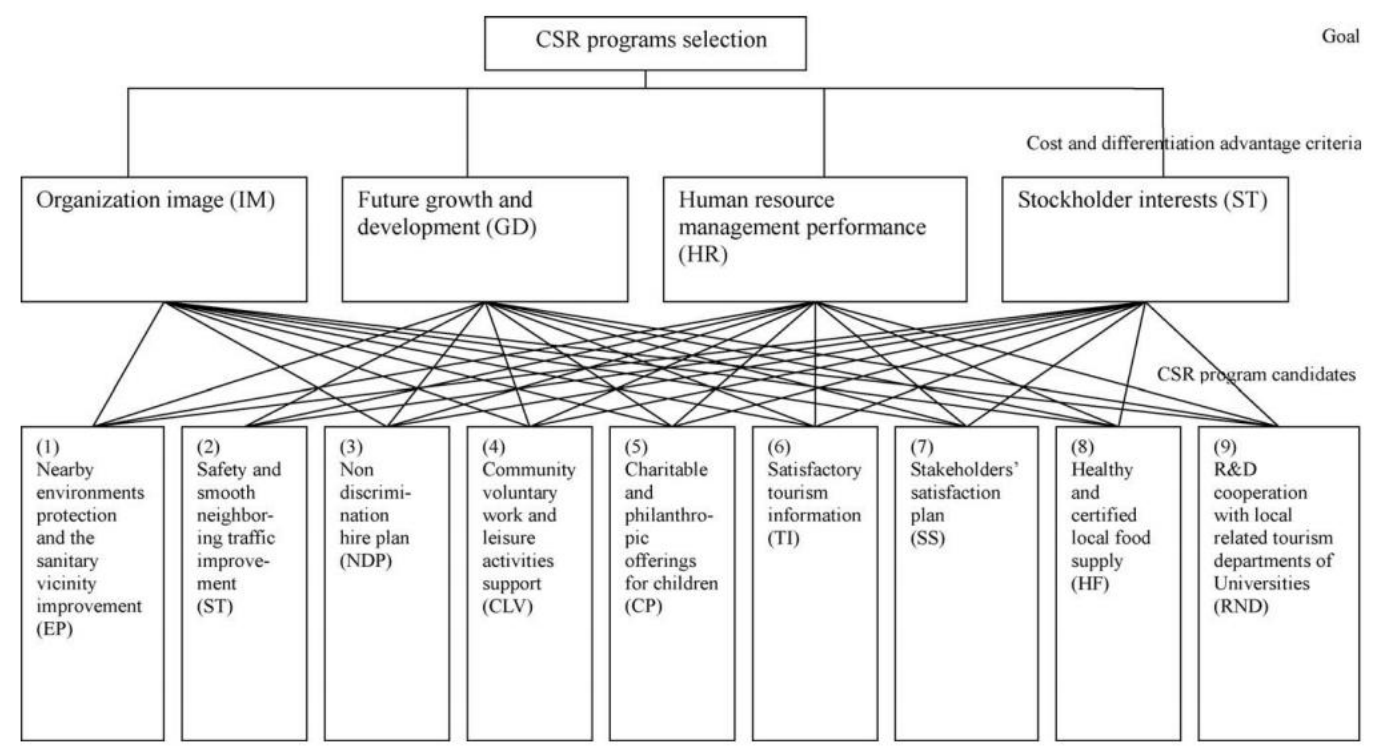

Figure 3. Analytic framework of international tourist hotels' CSR programs selection. 


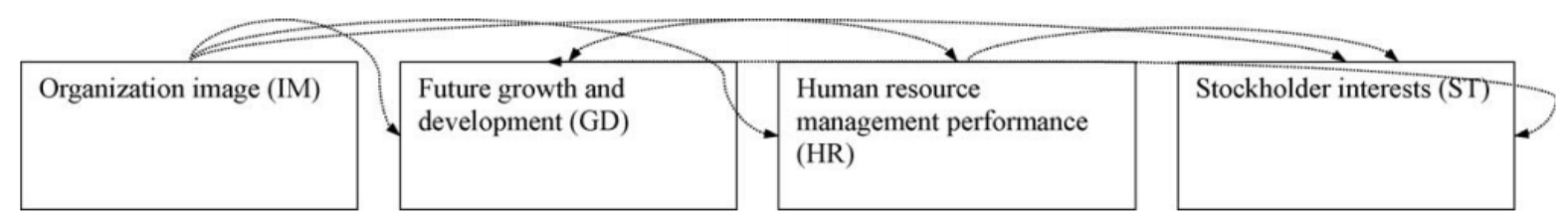

figure Interdependence among criteria in Fig. 3.

\section{CONCLUSions}

CIS mode of enterprise culture, integrated into the university professional theory, combined with the social practice of university enterprise cooperation, effectively the chain hotel management professional and cultural construction, improve the professional competitiveness, establish a chain hotel management professional new image, create a good professional brand, for the professional development in a new way, to cultivate the high quality talents for the future development of the hotel industry.

\section{REFERENCES}

[1] Agnihotri, R., Rapp, A.,. Perspectives on competitive intelligence within business: a tactical tool for salespeople to gain a competitive advantage. Mark.Rev. 201111 (4), 363-380.

[2] Ahmad, R., Ali, N.A., The use of cognitive mapping technique in management research: theory and practice. Manage. Res. News2003. 26 (7), 1-16.

[3] Ahmed, R.R., Ahmad, N., Khoso, I., Arif, K.A., Palwishah, R.I.,. Competitive Intelligence and marketing effectiveness of organizations: an investigation from Pakistan. Eur. Sci. J. 2014 10 (13), 342-353.

[4] Alonso-Almeida, M.D.M., Bremser, K., Llach, J., 2015. Proactive and reactive strategies deployed by restaurants in times of crisis: effects on capabilities, organization and competitive advantage. Int. J. Contemp. Hospitality Manage. 27 (7), 1641-1661.

[5] Aspinall, Y., Competitive intelligence in the biopharmaceutical industry: the key elements. Bus. Inf. Rev. 2011. 28 (2), 101104.
[6] Avci, U., Madanoglu, M., Okumus, F.,. Strategic orientation and performance of tourism firms: evidence from a developing country. Tourism Manage. 201132 (1), 147-157.

[7] Azma, F., Mostafapour, M.A.,. Business intelligence as a key strategy for development organizations. Procedia Technol. 2012 1, 102-106.

[8] Badr, A., Madden, E., Wright, S., The contribution of CI to the strategic decision making process: empirical study of the European pharmaceutical industry. J. Compet. Intell. Manage. 2006.3 (4), 15-35

[9] Breakspear, A.,. A new definition of intelligence. Intell. Natl. Secur. 201328 (5),678-693.

[10] Pereira-Moliner, J., Font, X., Tarí, J.J., Molina-Azorin, J.F., Lopez-Gamero, M.D,Pertusa-Ortega, E.M., 2015.

[11] The Holy Grail: environmental management,competitive advantage and business performance in the Spanish hotelindustry. Int. J. Contemp. Hospitality Manage. 27 (5), 714-738.

[12] Pelsmacker, P.D., Muller, M.-L., Viviers, W., Saayman, A., Cuyvers, L., Jegers, M.,2005. Competitive intelligence practices of South African and Belgianexporters. Mark. Intell. Plann. 23 (6/7), 606-620.

[13] Polit, D.F., Beck, T.C., Generalization in quantitative and qualitative research:myths and strategies. Int. J. Nurs. Stud. 2010.47 (11), 1451-1458.

[14] Pollina Corporate Real Estate Inc., 2012. Pollina Corporate Top 10ProBusinessStates, http://www.pollina.com/top10probusines s.html .

[15] Ponis, S.T., Christou, I.T.,. Competitive intelligence for SMEs: a web-based decision support system. Int. J. Bus. Inf. Syst 201312 (3), 243-258. 